Review Article

\title{
Radiofrequency Ablation for Treatment of Refractory Gastric Antral Vascular Ectasia: A Systematic Review of the Literature
}

\author{
M. Maida, S. Camilleri, M. Manganaro, S. Garufi, and G. Scarpulla \\ Section of Gastroenterology, S. Elia-M. Raimondi Hospital, Caltanissetta, Italy \\ Correspondence should be addressed to M. Maida; marcello.maida@hotmail.it
}

Received 2 May 2017; Revised 17 June 2017; Accepted 28 June 2017; Published 1 August 2017

Academic Editor: John N. Plevris

Copyright @ 2017 M. Maida et al. This is an open access article distributed under the Creative Commons Attribution License, which permits unrestricted use, distribution, and reproduction in any medium, provided the original work is properly cited.

\begin{abstract}
Background and Study Aims. GAVE is an uncommon cause of upper nonvariceal bleeding and often manifests itself as occult bleeding with chronic anemia. To date, the standard of care for GAVE is endoscopic treatment with thermoablative techniques. Despite good technical results, approximately two thirds of patients remain dependent on transfusions after the therapy. One of the emerging and more promising endoscopic treatments for GAVE is radiofrequency ablation (RFA). The aim of this study is to perform a systematic review of literature in order to assess current evidence supporting the effectiveness of this technique for treatment of refractory GAVE. Materials and Methods. Through electronic search, we identified 14 records, and after removal of duplicates and irrelevant studies, we selected 10 studies on radiofrequency ablation of GAVE: 4 prospective open-label singlecenter studies, 1 retrospective multicentric study, and 5 case reports. Results. Among all 72 treated patients reported in literature, $74.3 \%$ achieved a clinical response, while nonfatal AEs have been reported in $4.2 \%$ of cases. Conclusions. Despite some qualitative limitations, all literature data support effectiveness of RFA for treatment of refractory GAVE. In the future, large prospective controlled trials with adequate follow-up are needed to better assess the effectiveness and safety of this procedure.
\end{abstract}

\section{Introduction}

Gastric antral vascular ectasia (GAVE) is a relatively uncommon disorder, which accounts for $4 \%$ of nonvariceal upper GI bleeding. The first description of the disease dates back to 1953 when Rider et al. described a case of an "erosive type of gastritis with marked venocapillary ectasia" in a patient with chronic iron deficiency anemia [1].

The typical endoscopic picture of GAVE has been better defined in 1984 by Jabbari et al. [2] who described the presence of "longitudinal antral folds converging on the pylorus, containing visible columns of tortuous red ectatic vessels." Since endoscopic appearance of GAVE resembles the stripes of a watermelon, it is also known as the "watermelon stomach." The second, less frequent, variant of GAVE is a "diffuse form," in which red stripes are not visible and vascular ectasia presents itself with many angiodysplastic lesions in the antrum. In addition to its pathognomonic appearance, GAVE also presents sensitive, but not specific, histological features, namely, ectasia of mucosal capillaries, intravascular fibrin thrombosis, fibromuscular hyperplasia of the lamina propria, and spindle cell proliferation [3].

Diagnosis of GAVE is possible trough endoscopic detection of typical lesions and subsequent histological confirmation. Although diagnosis is generally easy, the therapeutic management of the disease is difficult and challenging. Most patients receive one or more treatments and require frequent blood transfusions, which result in a large number of hospital admissions and high costs.

Over time, several pharmacological, endoscopic, and surgical treatments have been proposed without fully satisfactory results [4-11].

The current standard of care for GAVE is endoscopic treatment with thermoablative techniques. Among these, one of the most widely used approaches is argon plasma coagulation (APC), a noncontact thermal method of hemostasis, which uses argon gas to deliver high-frequency current to the adjacent tissue [12-18]. Nevertheless, despite the initial effectiveness of endoscopic therapy, approximately two thirds of patients remain dependent on blood transfusions 
after treatment [19]. Beside this, also mechanical treatments such as endoscopic band ligation (EBL) have been proposed with promising results $[20,21]$.

One of the major emerging endoscopic treatments for GAVE is radiofrequency ablation (RFA) by the HALO system. This technology has been primarily developed and used for treatment of Barrett's esophagus with good results. Despite its original destination, the technique has also been used in the setting of lower gastrointestinal bleeding secondary to radiation proctitis $[22,23]$. Since ectatic vessels secondary to chronic radiation proctitis present features similar to gastric antral vascular ectasia, RFA has also been tested in the treatment of GAVE as follows.

Focal catheters (Barrx ${ }^{\mathrm{TM}} \mathrm{HALO}^{90}$ and HALO ${ }^{\text {ULTRA }}$ ) are installed on the distal end of the gastroscope. These devices present a bipolar electrode, with different surface sizes, and are provided with a flexible strap that slides over the tip.

Beside focal catheters, the Barrx through-the-scope (TTS) RFA catheter can be used. Unlike the former, this has a smaller surface and can be conveniently introduced trough the working channel, thus providing a greater maneuverability and avoiding multiple endoscope introductions (main specifications of devices are summarized in Table 1). After selection and setup of the catheter, the operator reaches the pathological gastric area and advances in order to allow the use of the device under direct vision. The catheter is placed against the target area at a 6 o'clock or 12 o'clock position, maintaining the big wheel of the endoscope, respectively, upwards or downwards to ensure maximum adherence with the tissue. Two to four consecutive pulses of energy can be delivered to the electrode in the same area (energy density of $12 \mathrm{~J} / \mathrm{cm}^{2}$ and power density of $40 \mathrm{~W} / \mathrm{cm}^{2}$ ) without moving the device or the electrode and keeping count of the total number of ablations. The electrode is therefore progressively repositioned to a new adjacent zone, starting at the pylorus and moving proximally, repeating the procedure until all the pathological gastric mucosa have been successfully treated. In order to maintain a correct energy delivery and to ensure full effectiveness in every area, the device needs to be removed and cleaned when the generator displays a reduced ablation percentage.

\section{Materials and Methods}

We performed a systematic review of the literature with the aim to summarize current evidences in support of radiofrequency ablation for GAVE and to better understand its effectiveness and its safety profile in this setting.

PubMed Central/Medline and Embase were searched systemically for English records up to December 2016 by two independent reviewers (M. M. and S. G.). Searches included combinations of the keywords "GAVE," "gastric antral vascular ectasia," or "antral vascular ectasia" with one or more of the following in both the title and/or the abstract: "thermal ablation," "radiofrequency ablation," "ablation," "RFA," "HALO," or "Barrx". Database searches were supplemented with literature searches of reference lists to find additional studies.
TABLE 1: Main technical specifications of RFA devices used for treatment of GAVE.

\begin{tabular}{lcccc}
\hline Devices & $\begin{array}{c}\text { Electrode } \\
\text { length }\end{array}$ & $\begin{array}{c}\text { Electrode } \\
\text { width }\end{array}$ & $\begin{array}{c}\text { Catheter } \\
\text { length }\end{array}$ & $\begin{array}{c}\text { Maximum } \\
\text { treatment per } \\
\text { session }\end{array}$ \\
\hline $\begin{array}{l}\text { Channel } \\
\text { catheter }\end{array}$ & $15.7 \mathrm{~mm}$ & $7.5 \mathrm{~mm}$ & $135 \mathrm{~cm}$ & 120 \\
HALO $^{60}$ & $15 \mathrm{~mm}$ & $10 \mathrm{~mm}$ & $160 \mathrm{~cm}$ & 80 \\
HALO $^{90}$ & $20 \mathrm{~mm}$ & $13 \mathrm{~mm}$ & $160 \mathrm{~cm}$ & 80 \\
HALO $^{\text {ULTRA }}$ & $40 \mathrm{~mm}$ & $13 \mathrm{~mm}$ & $160 \mathrm{~cm}$ & 80 \\
\hline
\end{tabular}

We considered eligible for the inclusion in this systematic review all original reports with the following characteristics: (1) inclusion of human subjects of any age treated with RFA for GAVE; (2) clear report of technical and clinical efficacy outcomes.

Studies investigating the effectiveness of other treatments for GAVE, alone or in combination with RFA, were excluded. Moreover, neither animal model studies nor nonoriginal reports (including reviews, systematic reviews, and metaanalysis) were included.

\section{Results}

Through electronic search strategies, 14 records have been identified, and after removal of duplicates and irrelevant studies, 10 studies have been finally selected: 4 prospective open-label single-center studies, 1 retrospective multicentric study, and 5 case reports (Table 2).

The first prospective open-label pilot study has been performed on 6 consecutive patients with GAVE, 4 of them refractory to APC, all treated by $\mathrm{HALO}^{90}$ ablation system for an average of 1.3 sessions per patient (ranging 1-3). All procedures resulted in a technical success with no adverse events, average hemoglobin increased from $8.6 \mathrm{~g} / \mathrm{dL}$ to $10.2 \mathrm{~g} / \mathrm{dL}$ after a 2 -month follow-up period, and 5 out of 6 patients maintained stable hemoglobin levels and were no longer dependent on blood transfusions [24].

A subsequent open-label prospective study has been performed on 21 patients, all of them failures after a minimum of $2 \mathrm{APC}$ sessions, and treated with HALO ${ }^{90}$ ULTRA catheter ablation system. Technical success was achieved in 19 out of 21 patients (90\%), while clinical success, defined as independence from transfusions after a 6-month follow-up period and negative endoscopy 6 months after treatment, was achieved in 18 out of 21 patients $(86 \%)$ with a mean hemoglobin increment from $8.6 \mathrm{~g} / \mathrm{dL}$ to $10.2 \mathrm{~g} / \mathrm{dL}$. Only two adverse events occurred, one minor acute bleeding and one superficial ulceration, both resolved without medical intervention [25].

Other two prospective open-label studies, performed on patients with refractory GAVE treated with RFA, recently confirmed these results.

The first study, conducted on 7 patients treated with the HALO ${ }^{\text {ULTRA }}$ system, showed technical and clinical effectiveness in all patients with a mean gain of hemoglobin from 9.3 to $10.1 \mathrm{~g} / \mathrm{dL}$ during a median follow-up of 6 months, in the absence of adverse events [26]. 
TABLE 2: Current available evidences on treatment of GAVE with radiofrequency ablation.

\begin{tabular}{|c|c|c|c|c|c|c|c|c|c|}
\hline Author & Year & Study level & Sample & RFA system & $\begin{array}{l}\text { Average } \\
\text { sessions }\end{array}$ & $\begin{array}{c}\text { Technical } \\
\text { success }\end{array}$ & Clinical success & AEs & $\begin{array}{c}\text { Follow-up } \\
\text { (months) }\end{array}$ \\
\hline Gross et al. [24] & 2008 & $\begin{array}{c}\text { Prospective } \\
\text { open-label } \\
\text { single center }\end{array}$ & 6 & HALO $^{90}$ & $\begin{array}{l}\text { Mean 1.7, } \\
\text { range (1-3) }\end{array}$ & $\begin{array}{c}6 / 6 \\
(100 \%)\end{array}$ & $\begin{array}{c}5 / 6(83 \%) \\
\text { Mean Hb gain } \\
8.6 \rightarrow 10.2\end{array}$ & None & 2 \\
\hline McGorisk et al. [25] & 2013 & $\begin{array}{c}\text { Prospective } \\
\text { open-label } \\
\text { single center }\end{array}$ & 21 & HALO $^{\text {ULTRA }}$ & $\begin{array}{l}\text { Median 2, } \\
\text { range (1-3) }\end{array}$ & $\begin{array}{l}19 / 21 \\
(90 \%)\end{array}$ & $\begin{array}{c}18 / 21(86 \%) \\
\text { Mean Hb gain } \\
7.8 \rightarrow 10.2\end{array}$ & $\begin{array}{c}2 / 21 \\
(9.5 \%)\end{array}$ & 6 \\
\hline Jana et al. [26] & 2015 & $\begin{array}{c}\text { Prospective } \\
\text { open-label } \\
\text { single center }\end{array}$ & 7 & HALO $^{\text {ULTRA }}$ & $\begin{array}{l}\text { Median 2, } \\
\text { range (1-3) }\end{array}$ & $\begin{array}{c}7 / 7 \\
(100 \%)\end{array}$ & $\begin{array}{c}5 / 7(71 \%) \\
\text { Mean Hb gain } \\
9.3 \rightarrow 10.1\end{array}$ & None & 6 \\
\hline Raza and Diehl [27] & 2015 & $\begin{array}{l}\text { Prospective } \\
\text { open-label } \\
\text { single center }\end{array}$ & 9 & $\mathrm{HALO}^{90}$ & $\begin{array}{l}\text { Median 3, } \\
\text { range (2-6) }\end{array}$ & $\begin{array}{c}9 / 9 \\
(100 \%)\end{array}$ & $\begin{array}{c}6 / 9(67 \%) \\
\text { Mean Hb gain } \\
7.3 \rightarrow 10.5\end{array}$ & None & 11 \\
\hline Dray et al. [28] & 2014 & $\begin{array}{l}\text { Retrospective } \\
\text { multicentric }\end{array}$ & 24 & $\begin{array}{c}\text { HALO }^{90} \text { or } \\
\text { HALO }^{\text {ULTRA }}\end{array}$ & $\begin{array}{c}\text { Mean } \\
1.8 \pm 0.8\end{array}$ & $\begin{array}{l}\text { Not } \\
\text { reported }\end{array}$ & $\begin{array}{c}15 / 24(62 \%) \\
\text { Mean Hb gain } \\
\quad 6.8 \rightarrow 9.8\end{array}$ & None & 6 \\
\hline Thandassery et al. [29] & 2014 & Case report & 1 & $\mathrm{HALO}^{90}$ & 2 & Yes & $\begin{array}{c}\text { Yes } \\
\text { Hb gain } \\
8 \rightarrow 12\end{array}$ & None & 1 \\
\hline Islam et al. [30] & 2014 & Case report & 1 & $\mathrm{HALO}^{\mathrm{TTS}}$ & 1 & Yes & $\begin{array}{c}\text { Yes } \\
\text { Hb gain } \\
6 \rightarrow 10.7\end{array}$ & None & 1 \\
\hline Ibáñez-Sanz et al. [31] & 2015 & Case report & 1 & $\mathrm{HALO}^{90}$ & 2 & Yes & $\begin{array}{c}\text { Yes } \\
\text { Hb gain } \\
7.5 \rightarrow 12\end{array}$ & None & 3 \\
\hline Trindade et al. [32] & 2016 & Case report & 1 & $\mathrm{HALO}^{\mathrm{Nd}}$ & 3 & Yes & Not reported & None & 6 \\
\hline Gaslightwala et al. [33] & 2014 & Case report & 1 & $\mathrm{HALO}^{90}$ & 4 & $\begin{array}{c}\text { Not } \\
\text { reported }\end{array}$ & Not reported & Yes & Not reported \\
\hline
\end{tabular}

Technical success: feasibility of therapy and complete endoscopic ablation of GAVE; clinical success: hemoglobin improvement and complete independence from the need for transfusions after follow-up; RFA: radiofrequency ablation; AEs: adverse events.

The second, performed on 9 patients treated with the HALO $^{90}$ system, confirmed a technical success in $100 \%$ of the patients and a clinical success in $67 \%$ of the patients after an 11-month follow-up period, in the absence of complications [27].

Despite the good results, all these studies are single center and don't present a randomized design. In addition, most of them present short follow-up periods; therefore, the long-term effectiveness of the therapy is not known.

One recent retrospective multi-center open-label study performed in over 8 endoscopic centers in Europe and the USA, revised a series of 24 patients with GAVE who underwent thermoablation with the HALO system, 18 of them refractory to previous medical or endoscopic therapy and 23 with transfusion-dependent anemia. After a follow-up period of 6 months, all of them reduced their transfusional request, 15 out of $24(65.2 \%)$ were no longer dependent on transfusions and an increase in hemoglobin levels (from $6.8 \pm 1.4$ to $9.8 \pm 1.8 \mathrm{~g} / \mathrm{dL}$ ) was observed in all patients [28]. Like previous studies, this multicentric experience confirmed that RFA with HALO system is effective and safe for the treatment of GAVE. Similarly, other reports showed a good efficacy and safety of the procedure, in the absence of major side effects [29-32]. Only one case reported the occurrence of bacteremia and sepsis after RFA, which were resolved after antibiotic therapy [33].

\section{Discussion}

Despite recent technological advances, therapeutic management of GAVE is still challenging and presents many pitfalls.

Over time several pharmacological, endoscopic and surgical treatments have been proposed without satisfactory results. Medical therapy has yielded poor results, with high rates of adverse events [4-11], while surgical options, such as antrectomy, are curative but burdened by high morbidity and mortality and are no longer used in clinical practice.

The current standard of care is endoscopic treatment with thermoablative techniques. To date, some studies have proven the efficacy of APC in the treatment of GAVE, showing promising clinical outcomes with an improvement of anemia and a reduction of blood transfusion requests over time [12-18]. Nevertheless, most of these studies have been performed on small sample sizes with a short follow-up period, and few data exist on long-term outcomes. 
Endoscopic band ligation (EBL) is already being widely used for the treatment of upper and lower vascular diseases. It is considered to be safer and cheaper than ablative techniques. A recent prospective study performed on 21 subjects with GAVE treated with EBL showed a clinical response in $91 \%$ of patients with a significant improvement in the mean hemoglobin levels and a significant decrease in blood transfusion requirements in the absence of major complications [20].

Despite good technical results of these techniques, a considerable proportion of patients relapses after endoscopic therapy and little is known regarding proper therapeutic strategies to apply for refractory GAVE.

Radiofrequency ablation with the Barrx system is a new, promising technique for endoscopic treatment of GAVE. The data synthesis deriving from this systematic review shows that, among all 72 treated patients reported in the literature, $74.3 \%$ achieved a clinical response, minor AEs occurred in $4.2 \%$ of cases, and no fatal AEs have been reported. Nevertheless, all these studies present some qualitative limitations. Most of them were performed on small samples, in a single center, and none of them were controlled. In addition, all were characterized by a short follow-up, making it difficult to assess the real rates of long-term clinical response after RFA.

Furthermore, a validated treatment schedule is absent. Some authors perform RFA with focal catheters, while others use through-the-scope (TTS) catheter. Moreover, in most centers, RFA is repeated every $4-8$ weeks until there is evidence of complete endoscopic healing of the disease, while in other centers, the procedure is performed "on-demand" based on clinical response.

Best intervals, as well as catheter type and size, should ideally be identified on the basis of proper prospective or, alternatively, observational studies demonstrating a better performance of one or the other in achieving a technical and clinical success.

One further point must be made about costs. Considering a single session, RFA devices are more expensive than APC. On the other hand, it must be pointed out that RFA requires a lower number of sessions and, if effective, it could also reduce secondary costs related to repeated hospitalizations, endoscopic procedures, and blood transfusions.

\section{Conclusions}

Results from this systematic review suggest that radiofrequency ablation is a valuable therapeutic tool for treatment of refractory gastric antral vascular ectasia.

Current literature data support the effectiveness and safety of this procedure for treatment of GAVE, in the absence of major adverse events. Unfortunately, most of these evidences are burdened by qualitative limitations; therefore, in the future, larger prospective controlled trials with adequate follow-up are needed to better assess the clinical efficacy of the technique, as well as a validated treatment schedule. Finally, a cost analysis should be performed in order to estimate the cost effectiveness of radiofrequency ablation compared to other techniques currently in use.

\section{Conflicts of Interest}

The authors declare that there is no conflict of interest regarding the publication of this paper.

\section{Authors' Contributions}

M. Maida and G. Scarpulla are guarantors of the integrity of the entire study and contributed to the manuscript drafting and manuscript revision for important intellectual content; M. Maida, S. Camilleri, and G. Scarpulla contributed to the manuscript editing; all authors contributed to writing the paper and had full control over the preparation of the manuscript; all authors approved the final draft manuscript.

\section{References}

[1] J. A. Rider, A. P. Klotz, and J. B. Kirsner, "Gastritis with venocapillary ectasia as a source of massive gastric hemorrhage," Gastroenterology, vol. 24, pp. 118-123, 1953.

[2] M. Jabbari, R. Cherry, J. O. Lough, D. S. Daly, D. G. Kinnear, and C. A. Goresky, "Gastric antral vascular ectasia: the watermelon stomach," Gastroenterology, vol. 87, pp. 1165-1170, 1984.

[3] P. F. Suit, R. E. Petras, T. W. Bauer, and J. L. Petrini, "Gastric antral vascular ectasia. A histologic and morphometric study of "the watermelon stomach"," The American Journal of Surgical Pathology, vol. 11, pp. 750-757, 1987.

[4] D. Harrison, "Use of oestrogen in the treatment of familial hemorrhagic telangiectasia," Laryngoscope, vol. 92, pp. 314319, 1982.

[5] J. Panés, M. Casadevall, M. Fernández et al., "Gastric microcirculatory changes of portal hypertensive rats can be attenuated by long-term oestrogen progesterone treatment," Hepatology, vol. 20, pp. 1261-1270, 1994.

[6] E. Van Custem, P. Rutgerts, and G. van Trappen, "Treatment of bleeding gastrointestinal vascular malformations with oestrogen progesterone," Lancet, vol. 335, pp. 953-955, 1990.

[7] A. Tran, J. P. Villeneuve, M. Bilodeau et al., "Treatment of chronic bleeding from gastric antral vascular ectasia (GAVE) with oestrogen-progesterone in cirrhotic patients: an open pilot study," The American Journal of Gastroenterology, vol. 94, no. 10, pp. 202-211, 1994.

[8] G. Nardone, A. Rocco, T. Balzano, and G. Budillon, "The efficacy of octreotide therapy in chronic bleeding due to vascular abnormalities of the gastrointestinal tract," Alimentary Pharmacology \& Therapeutics, vol. 13, pp. 1429-1436, 1999.

[9] R. Weitgasser, P. Sungler, C. Hauser-Kronberger, O. Dietze, P. Sattlegger, and G. W. Hacker, "Immunohistochemical assessment of an asymptomatic glucagonoma in a patient with hypergastrinemia and marked antral angiodysplasia," Applied Immunohistochemistry \& Molecular Morphology, vol. 9, no. 1, pp. 92-96, 2001.

[10] G. Barbara, R. De Giorgio, B. Salvioli, V. Stanghellini, and R. Corinaldesi, "Unsuccessful octreotide treatment of the watermelon stomach," Journal of Clinical Gastroenterology, vol. 26, pp. 345-346, 1998.

[11] R. H. Park, B. J. Danesh, R. Upadhyay, A. G. Howatson, F. D. Lee, and R. I. Russell, "Gastric antral vascular ectasia (watermelon stomach) - therapeutic options," Postgraduate Medical Journal, vol. 66, pp. 720-723, 1990. 
[12] A. Probst, R. Scheubel, and M. Wienbeck, "Treatment of watermelon stomach (GAVE syndrome) by means of endoscopic argon plasma coagulation (APC): long-term outcome," Zeitschrift für Gastroenterologie, vol. 39, pp. 447-452, 2001.

[13] I. Yusoff, F. Brennan, D. Ormonde, and B. Laurence, "Argon plasma coagulation for treatment of watermelon stomach," Endoscopy, vol. 34, pp. 407-410, 2002.

[14] S. Sebastian, R. McLoughlin, A. Qasim, C. A. O'Morain, and M. J. Buckley, "Endoscopic argon plasma coagulation for the treatment of gastric antral vascular ectasia (watermelon stomach): long-term results," Digestive and Liver Disease, vol. 36, pp. 212-217, 2004.

[15] V. Kwan, M. J. Bourke, S. J. Williams et al., “Argon plasma coagulation in the management of symptomatic gastrointestinal vascular lesions: experience in 100 consecutive patients with long-term follow-up," The American Journal of Gastroenterology, vol. 101, pp. 58-63, 2006.

[16] S. Lecleire, E. Ben-Soussan, M. Antonietti et al., "Bleeding gastric vascular ectasia treated by argon plasma coagulation: a comparison between patients with and without cirrhosis," Gastrointestinal Endoscopy, vol. 67, pp. 219-225, 2008.

[17] S. Herrera, J. M. Bordas, J. Llach et al., "The beneficial effects of argon plasma coagulation in the management of different types of gastric vascular ectasia lesions in patients admitted for GI hemorrhage," Gastrointestinal Endoscopy, vol. 68, pp. 440-446, 2008.

[18] Y. C. Chiu, L. S. Lu, K. L. Wu et al., "Comparison of argon plasma coagulation in management of upper gastrointestinal angiodysplasia and gastric antral vascular ectasia hemorrhage," BMC Gastroenterology, vol. 12, p. 67, 2012.

[19] S. Sebastian, C. A. O'Morain, and M. J. Buckley, "Review article: current therapeutic options for gastric antral vascular ectasia," Alimentary Pharmacology \& Therapeutics, vol. 18, no. 2, pp. 157-165, 2003.

[20] S. Zepeda-Gómez, R. Sultanian, C. Teshima, G. Sandha, S. Van Zanten, and A. J. Montano-Loza, "Gastric antral vascular ectasia: a prospective study of treatment with endoscopic band ligation," Endoscopy, vol. 47, no. 6, pp. 538-540, 2015.

[21] C. D. Wells, M. E. Harrison, S. R. Gurudu et al., "Treatment of gastric antral vascular ectasia (watermelon stomach) with endoscopic band ligation," Gastrointestinal Endoscopy, vol. 68, pp. 231-236, 2008.

[22] C. Zhou, D. C. Adler, L. Becker et al., "Effective treatment of chronic radiation proctitis using radiofrequency ablation," Therapeutic Advances in Gastroenterology, vol. 2, pp. 149156, 2009.

[23] T. Rustagi and H. Mashimo, "Endoscopic management of chronic radiation proctitis," World Journal of Gastroenterology, vol. 17, pp. 4554-4562, 2011.

[24] S. A. Gross, M. Al-Haddad, K. R. Gill, A. N. Schore, and M. B. Wallace, "Endoscopic mucosal ablation for the treatment of gastric antral vascular ectasia with the HALO90 system: a pilot study," Gastrointestinal Endoscopy, vol. 67, no. 2, pp. 324-327, 2008.

[25] T. McGorisk, K. Krishnan, L. Keefer, and S. Komanduri, "Radiofrequency ablation for refractory gastric antral vascular ectasia (with video)," Gastrointestinal Endoscopy, vol. 78, no. 4, pp. 584-588, 2013.

[26] T. Jana, N. Thosani, M. B. Fallon, A. W. Dupont, and A. Ertan, "Radiofrequency ablation for treatment of refractory gastric antral vascular ectasia (with video)," Endoscopy International Open, vol. 3, no. 2, pp. E125-E127, 2015.

[27] N. Raza and D. L. Diehl, "Radiofrequency ablation of treatment-refractory gastric antral vascular ectasia (GAVE)," Surgical Laparoscopy, Endoscopy \& Percutaneous Techniques, vol. 25, no. 1, pp. 79-82, 2015.

[28] X. Dray, A. Repici, P. Gonzalez et al., "Radiofrequency ablation for the treatment of gastric antral vascular ectasia," Endoscopy, vol. 46, no. 11, pp. 963-969, 2014.

[29] R. Thandassery, A. Jha, and M. Goenka, "Gastrointestinal: radiofrequency ablation in the management of refractory gastric antral vascular ectasia," Journal of Gastroenterology and Hepatology, vol. 29, no. 5, p. 894, 2014.

[30] R. S. Islam, S. F. Pasha, and D. E. Fleischer, "Refractory gastric antral vascular ectasia treated by a novel through-the-scope ablation catheter," Gastrointestinal Endoscopy, vol. 80, no. 5, pp. 896-897, 2014.

[31] G. Ibáñez-Sanz, L. Rivas, E. Melilli, J. Guardiola, C. Baliellas, and J. B. Gornals, "Endoscopic radiofrequency ablation for APC refractory gastric antral vascular ectasia using the HALO90 system in a kidney transplant candidate," Revista Española de Enfermedades Digestivas, vol. 107, no. 5, pp. 307-308, 2015.

[32] A. J. Trindade, S. Inamdar, and D. Magier, "Radiofrequency ablation of gastric antral vascular ectasia of the gastric cardia," Endoscopy, vol. 48, no. S 01, article E301, 2016.

[33] I. Gaslightwala and D. L. Diehl, "Bacteremia and sepsis after radiofrequency ablation of gastric antral vascular ectasia," Gastrointestinal Endoscopy, vol. 79, no. 5, pp. 873-874, 2014. 


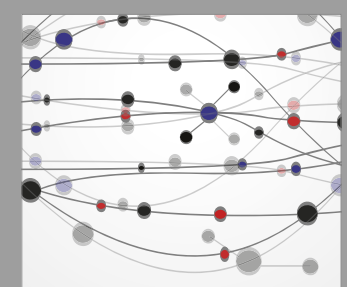

The Scientific World Journal
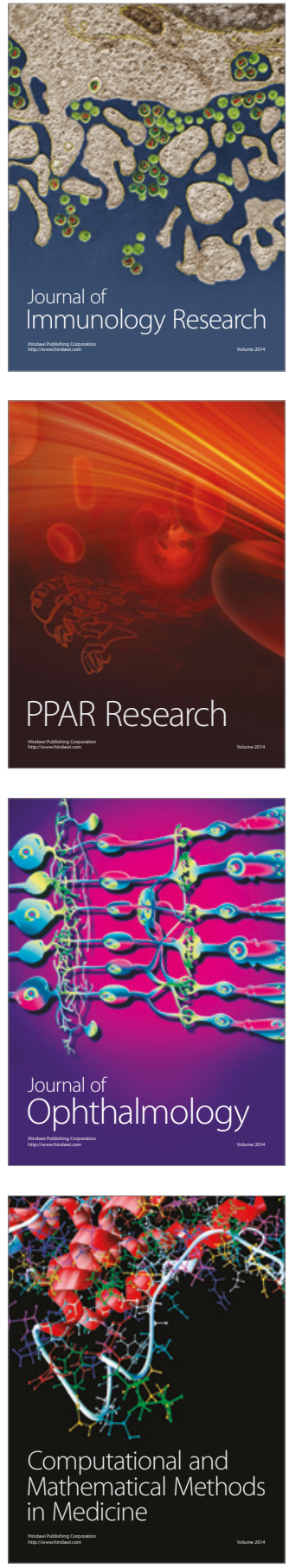

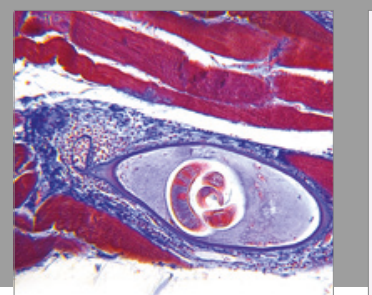

Gastroenterology Research and Practice
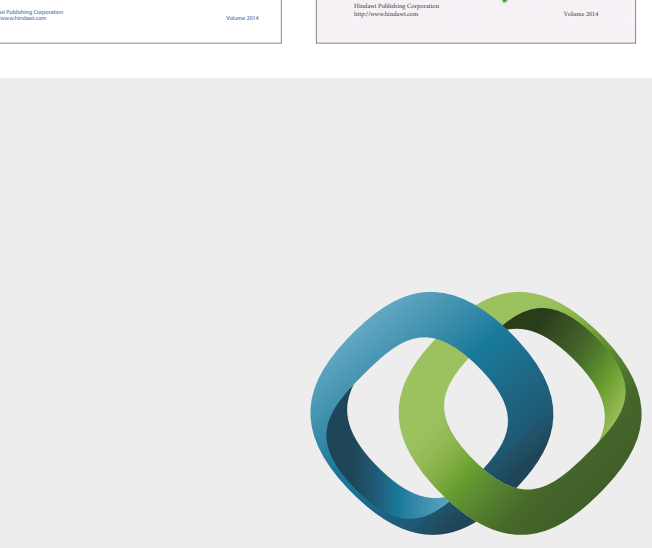

\section{Hindawi}

Submit your manuscripts at

https://www.hindawi.com
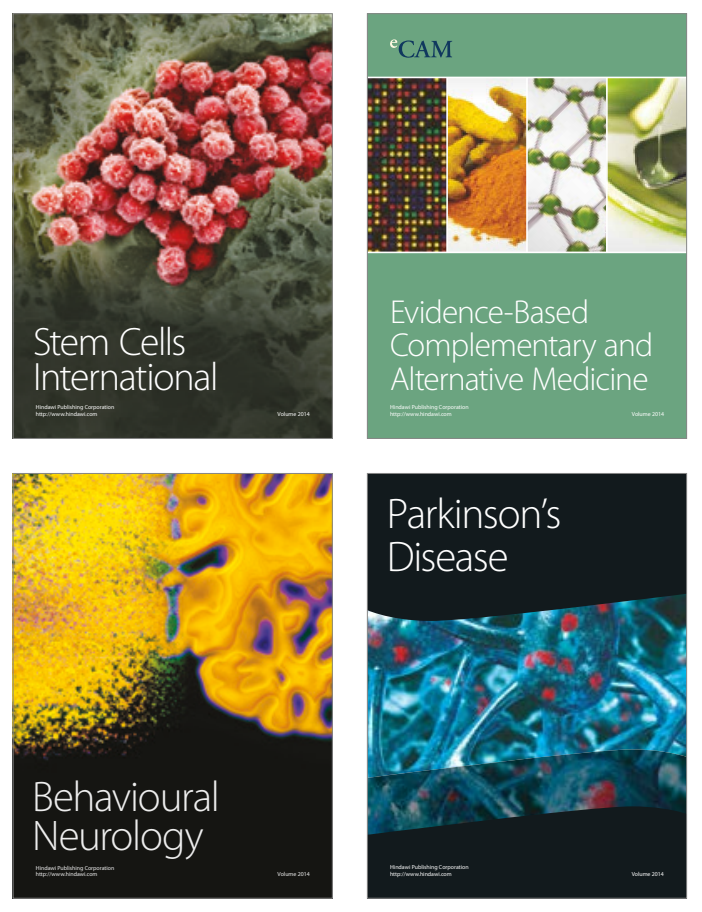
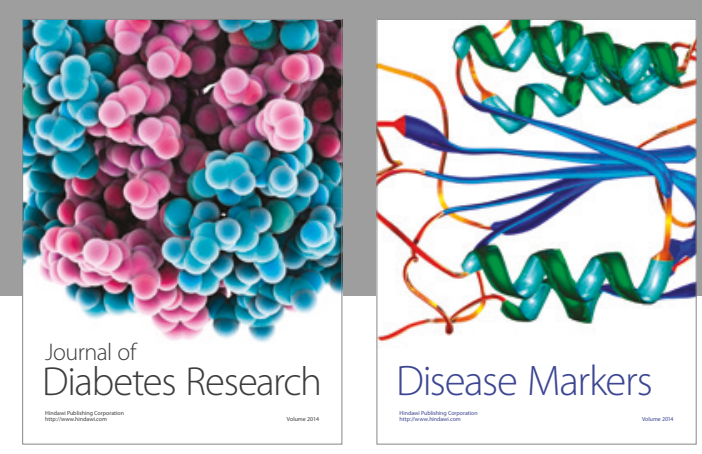

Disease Markers
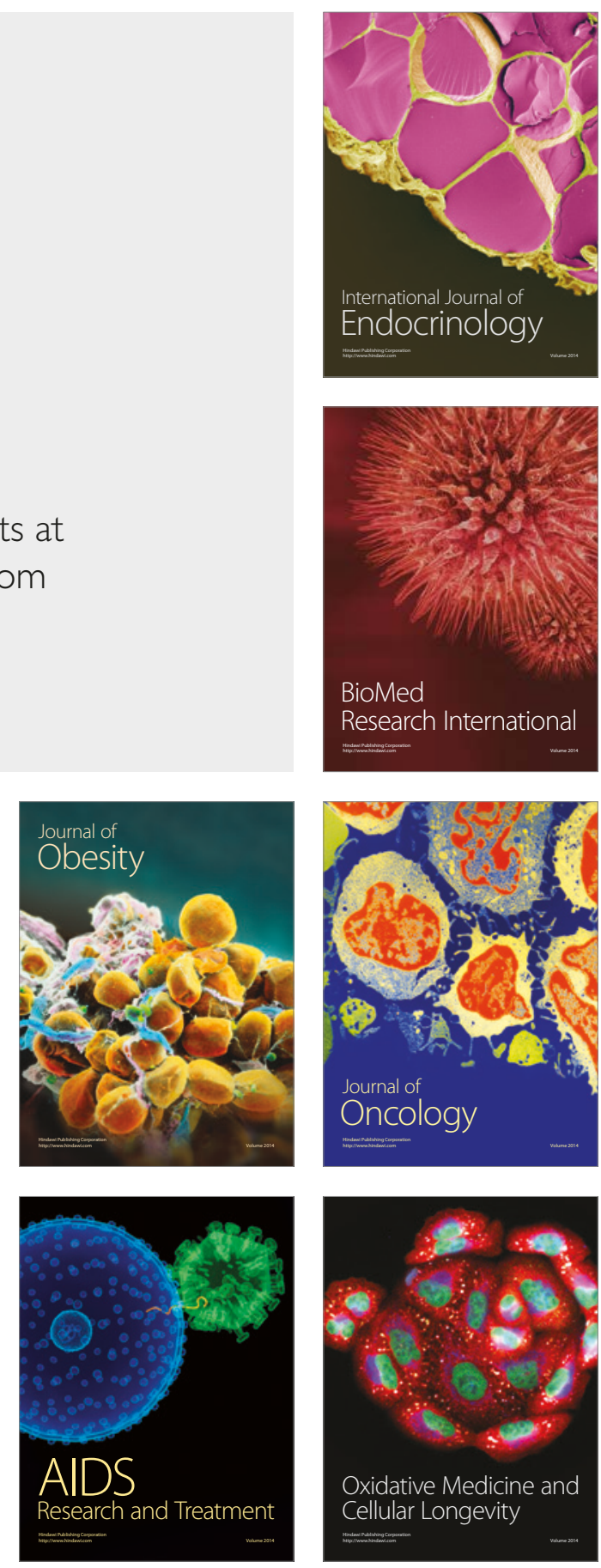